\title{
Mechanical Characterization of a Nano-ODS Steel Prepared by Low-Energy Mechanical Alloying
}

\author{
Massimo De Sanctis ${ }^{1}$, Alessandra Fava ${ }^{2, *}$, Gianfranco Lovicu ${ }^{1,+}{ }^{\text {, Roberto Montanari }}{ }^{2}$, \\ Maria Richetta $^{2}$, Claudio Testani ${ }^{3, \ddagger}$ (DD and Alessandra Varone ${ }^{2}$ \\ 1 Department of Civil and Industrial Engineering, University of Pisa, Largo Lucio Lazzarino 2, \\ 56122 Pisa, Italy; m.desanctis@ing.unipi.it (M.D.S.); lovicu.gf@gmail.com (G.L.) \\ 2 Department of Industrial Engineering, University of Rome "Tor Vergata", Via del Politecnico 1, \\ 00133 Rome, Italy; roberto.montanari@uniroma2.it (R.M.); richetta@uniroma2.it (M.R.); \\ alessandra.varone@uniroma2.it (A.V.) \\ 3 Centro Sviluppo Materiali S.p.A., Via di Castel Romano 100, 00128 Rome, Italy; c.testani@libero.it \\ * Correspondence: alessandra.fava@uniroma2.it; Tel.: +39-06-7259-7180 \\ + Current address: Nuovo Pignone Spa, GE O\&G, Via Felice Matteucci 2, 50127 Firenze, Italy. \\ $\ddagger$ Current address: CALEF-ENEA Centro Ricerche Casaccia, Via Anguillarese 301, 00123 Santa Maria di Galeria, \\ Rome, Italy.
}

Received: 22 June 2017; Accepted: 21 July 2017; Published: 25 July 2017

\begin{abstract}
An oxide dispersion strengthened (ODS) ferritic steel with nanometric grain size has been produced by low-energy mechanical alloying (MA) of steel powder ( $\mathrm{Fe}-14 \mathrm{Cr}-1 \mathrm{~W}-0.4 \mathrm{Ti})$ mixed with $\mathrm{Y}_{2} \mathrm{O}_{3}$ particles $(0.3 \mathrm{wt} \%)$ and successive hot extrusion (HE). The material exhibits superior mechanical properties with respect to the unreinforced steel up to $400{ }^{\circ} \mathrm{C}$; then such differences tend to progressively decrease and at $700{ }^{\circ} \mathrm{C}$ yield stress (YS) and ultimate tensile strength (UTS) values are very close. The microstructure and mechanical behaviour have been compared with those of ODS steels prepared by the most common process, high-energy MA, consolidation through hot isostatic pressing (HIP) or hot extrusion (HE), annealing around $1100^{\circ} \mathrm{C}$ for $1-2 \mathrm{~h}$. The main strengthening mechanisms have been examined and discussed to explain the different behaviour. In addition, heat treatments in the range $1050-1150{ }^{\circ} \mathrm{C}$ were carried out and a microstructural evolution with a relevant hardness decrease has been observed. TEM observations evidenced defect recovery and partial grain coarsening owing to the not perfectly homogeneous distribution of oxide particles.
\end{abstract}

Keywords: ODS steel; nanostructure; low-energy mechanical alloying; mechanical properties; heat treatments; strengthening mechanisms

\section{Introduction}

Oxide dispersion strengthened (ODS) ferritic steels are candidate materials for applications in fission and fusion nuclear reactors [1-4]. In order to improve the thermal efficiency of reactors, their operational temperature (up to $\sim 800{ }^{\circ} \mathrm{C}$ ) [5] must be increased thus good high temperature mechanical properties and creep resistance are strict requirements for structural materials. In the case of ODS steels, the target is achieved by an uniform dispersion of very fine oxide particles, in general $\mathrm{Y}_{2} \mathrm{O}_{3}$, and by the addition of a small amount of Ti which has the effect to reduce oxide particles to a size of few nanometres; the physical mechanism has been explained by Ukai et al. [1]. The strengthening due to the fine particle distribution is effective through two mechanisms: (i) by hindering dislocation motion, and (ii) by inhibiting recovery and recrystallization. A further contribution to enhance high-temperature performances can also be obtained through grain refinement. An optimal solution is the combination of the effects of oxide dispersion strengthening and ultra-fine grains [6,7]. Furthermore, oxide nanoparticles in the steel matrix act as sinks for point defects thus improve the resistance 
to neutron radiation damage [8] and reduce irradiation embrittlement [9], swelling, and damage accumulation [10].

ODS steels are commonly prepared by high-energy mechanical alloying (MA) of a mixture of steel powder and $\mathrm{Y}_{2} \mathrm{O}_{3}$ particles followed by a consolidation stage consisting of hot isostatic pressing (HIP) or hot extrusion (HE) [11,12]. The samples are then submitted to annealing around $1100{ }^{\circ} \mathrm{C}$ for $1-2 \mathrm{~h}$. In the last years the attention has been focused on Spark Plasma Sintering (SPS), a novel pressure assisted consolidation technology characterized by high heating rate, low sintering temperature, and short isothermal time at sintering temperature $[13,14]$. In the past, it has been successfully used by one of the authors to process nanostructured Fe-Mo powders [15] and more recently applied to ODS steels by Ji et al. [16]. Even if Boulnat et al. [17] were able to process a semi-industrial dense pellet $(0.5 \mathrm{~kg})$ of ODS ferritic steel, large mechanical parts are in general quite difficult and expensive to prepare by means of SPS.

High-energy MA decomposes $\mathrm{Y}_{2} \mathrm{O}_{3}$ into $\mathrm{Y}$ and $\mathrm{O}$ atoms, which are then homogeneously dissolved into the ferritic matrix of steel. The annealing around $1100{ }^{\circ} \mathrm{C}$ causes the dissolved $\mathrm{Y}$ and $\mathrm{O}$ atoms to bond with $\mathrm{Ti}$ and precipitate to form extremely fine Y-Ti-O complex oxides [1]. An undesired consequence of such procedure is that the high temperature annealing causes the equiaxed nanometric grains obtained by MA to evolve towards a bimodal grain size distribution. Such microstructure involves a significant decrease of hardness, yield stress, and ultimate tensile strength together with an increase of ductility, and most importantly, strongly anisotropic mechanical properties. Such anisotropy depends on the combined effect of bundle-like structures of elongated grains with aggregates of small-size grains and precipitation along the extrusion direction [18].

The aim of this work is to assess the mechanical behaviour of an ODS steel prepared through a novel route devised to process larger amounts of powder (of the order of kilograms) with respect to the conventional process and to avoid bimodal grain size distribution. MA was carried out through a horizontally rotating low-energy dry-ball miller (capability of about $6 \times 10^{-3} \mathrm{~m}^{3}$ ). ODS steel was prepared using a mixture of Fe-14Cr-1W-0.4Ti steel powder added with $0.3 \mathrm{wt} \% \mathrm{Y}_{2} \mathrm{O}_{3}$. Consolidation was made through $\mathrm{HE}$ without the final annealing at $1100^{\circ} \mathrm{C}$.

The mechanical characteristics have been examined through tensile tests carried out at increasing temperature up to $700{ }^{\circ} \mathrm{C}$ and hardness tests. The same tests have been made on the ODS after heat treatments up to $1150{ }^{\circ} \mathrm{C}$ for different soaking times to evaluate the microstructural and mechanical stability after exposure at high temperature.

\section{Materials and Methods}

The ODS has been prepared from pre-alloyed steel powder (Nanoval, Germany) produced by vacuum gas atomization with the following composition: $\mathrm{Cr}$ 14, W 1, Ti 0.4, Mn 0.3, Si 0.3, Ni 0.15, $\mathrm{Cu} \leq 0.03, \mathrm{~V} \leq 0.02, \mathrm{Mo} \leq 0.01, \mathrm{Al} \leq 0.01, \mathrm{C} \leq 0.01, \mathrm{~N} \leq 0.007, \mathrm{P} \leq 0.008, \mathrm{~S} \leq 0.001, \mathrm{Co} \leq 0.005$, $\mathrm{Ta} \leq 0.005, \mathrm{Nb}, \mathrm{Sn}, \mathrm{Sb}$, As and $\mathrm{Ag} \leq 0.002$, Fe to balance (wt \%). Nanoparticles of $\mathrm{Y}_{2} \mathrm{O}_{3}(0.3 \mathrm{wt} \%)$ (produced by Plasma \& Ceramic Technologies (PCT) Ltd., Salaspils, Latvia), smaller than $50 \mathrm{~nm}$ have been mixed to the steel powder, then the mixture has been mechanically alloyed in vacuum $\left(10^{-4} \mathrm{mbar}\right)$.

A large scale horizontally rotating low-energy dry-ball miller manufactured in house at Centro Sviluppo Materiali S.p.A. (CSM) with a capability of about $6 \times 10^{-3} \mathrm{~m}^{3}$ was employed in present experiments [19]. Steel balls of AISI 316 steel with two different diameters ( 2.5 and $10 \mathrm{~mm})$ in a 1:10 ratio with the powder weight to be mixed were put in a stainless steel jar (homemade: Centro Sviluppo Materiali S.p.A.) with diameter of $200 \mathrm{~mm}$. All the procedures of powder manipulation and jar sealing were carried out in a glove box and in Ar- $2 \% \mathrm{H}$ atmosphere to avoid oxygen pick-up during MA process; the jar rotated for $300 \mathrm{~h}$ at $60 \mathrm{rpm}$. The energy $\Delta E$ transferred per hit and per unit of mass depends on the rotation speed $\omega_{p}$ of the planetary mill for each ball diameter $d_{b}$ and has been estimated through the relationship proposed by Magini and Iasonna [20]:

$$
\Delta E / Q_{\mathrm{MAX}}=\left[7.66 \times 10^{-2} R_{p}^{1.2} \zeta^{0.6} E^{0.4}\right] d_{b} \omega_{p}^{1.2} / \sigma
$$


where $Q_{\mathrm{MAX}}$ is the maximum quantity of trapped material, $R_{p}$ the radius of the plate of the mill, $\zeta$ the ball material density, $E$ the Young's modulus, $\sigma$ the surface density of the powder covering the balls. In the conditions of present experiment, the quantity $\Delta E / Q_{\mathrm{MAX}}$ is $\sim 11 \mathrm{~J} / \mathrm{g}$.hit, whereas it reaches a value of $\sim 75 \mathrm{~J} / \mathrm{g}$.hit with high-energy MA with a rotation speed of $300 \mathrm{rpm}$.

To assess possible microstructural changes in the temperature range of ODS applications, powders of the steel with reinforcement particles after MA have been heat treated for $2 \mathrm{~h}$ at $800{ }^{\circ} \mathrm{C}$. For comparison steel powder without the reinforcement have been submitted to the same treatment.

Finally, to get the densification cylindrical containers were filled with the powder, evacuated to a pressure of $3 \times 10^{-4}$ mbar, sealed and subjected to $\mathrm{HE}$ at $1100{ }^{\circ} \mathrm{C}$.

Part of the material has been examined in as-prepared condition, another part has been submitted to the heat treatments at 1050,1100 , and $1150{ }^{\circ} \mathrm{C}$ for $30 \mathrm{~min}$ (samples $\mathrm{A}, \mathrm{B}, \mathrm{C}$ ).

Transmission electron microscopy (TEM) analysis has only been done to observe possible microstructural inhomogeneities (defect recovery and grain size) and the dimension of the small oxide particles. TEM observations were carried out by using a Jeol-3002FS-High Resolution STEM (resolution 0.19 nanometers- source field emission gun) and a Philips CM12 microscope (Philips Electron Optics, Eindhoven, The Netherlands) equipped with a Bruker Quantax TEM 200T EDX system (Bruker, Berlin, Germany). Thin foils have been prepared by mechanical grinding followed by double-jet electropolishing (Materials Science N.W. Ltd, Settle, England) in a solution of 10\% perchloric acid $+90 \%$ ethylene glycol monobutyl ether at $-20^{\circ} \mathrm{C}(30 \mathrm{~V}, 8.5 \mathrm{~mA})$.

$X$-ray diffraction (XRD) spectra were collected using Mo-K $\alpha$ radiation $(\lambda=0.07093 \mathrm{~nm})$ in step-scanning mode with $2 \theta$ steps of $0.05^{\circ}$ and counting time of $5 \mathrm{~s}$ per step. High precision peak profiles were recorded with $2 \theta$ steps of $0.005^{\circ}$ to determine the mean micro-strain $\varepsilon$ [21] and then to calculate the dislocation density $\rho$ by means of the Williamson-Smallman relationship [22]:

$$
\rho=\frac{\Xi \varepsilon^{2}}{k_{0} b^{2}}
$$

where $\Xi=16$ a constant, $b=0.25 \mathrm{~nm}$ the modulus of Burgers vector and $k_{0} \cong 1$ a factor depending on dislocation interaction.

Vickers microhardness $(100 \mathrm{~g} / 10 \mathrm{~s})$ and tensile tests have been made to verify the effectiveness of the MA process. Tensile tests $\left(\dot{\varepsilon}=10^{-3} \mathrm{~s}^{-1}\right)$ at increasing temperature from $25^{\circ} \mathrm{C}$ up to $700{ }^{\circ} \mathrm{C}$ have been carried out on ODS and, for comparison, on unreinforced steel. Tensile probes had a diameter of $4 \mathrm{~mm}$ and a gauge length of $16.5 \mathrm{~mm}$.

To determine the value of shear modulus $G$ at increasing temperature, Mechanical Spectroscopy (MS) experiments with bar-shaped samples (length $60 \mathrm{~mm}$, width $7 \mathrm{~mm}$, thickness $0.5 \mathrm{~mm}$ ) have been made by means of VRA 1604 apparatus (CANTIL Srl, Bologna, Italy) [23] with a heating rate of $1^{\circ} \mathrm{C} / \mathrm{min}$.

\section{Results}

The peculiar characteristic of ODS steels is a sub-micron dimension of grains and a massive dispersion of nanometric oxide particles within the matrix, very effective in hindering the dislocation motion and increasing mechanical properties of the material. Final properties strongly depend on the microstructural features induced by the preparation route which have been monitored step by step. For the sake of clarity, the results will be presented in three sections:

(i) Original powders and ODS precursor;

(ii) Hot extruded material;

(iii) eat treated ODS steel.

\subsection{Original Powders and ODS Precursor}

The particles of steel powder (Figure 1a) used in present experiments had a near spherical shape and bimodal size distribution peaked at 4 and $20 \mu \mathrm{m}$. They were mixed with spherical nanoparticles 
of $\mathrm{Y}_{2} \mathrm{O}_{3}$ smaller than $50 \mathrm{~nm}$ (Figure 1b) and processed by low-energy MA. As shown in Figure 1c, after $300 \mathrm{~h}$ of treatment it is no more possible to distinguish the original steel and $\mathrm{Y}_{2} \mathrm{O}_{3}$ particles: the resulting particles exhibit an irregular shape and an almost homogeneous size of about $35 \mu \mathrm{m}$.

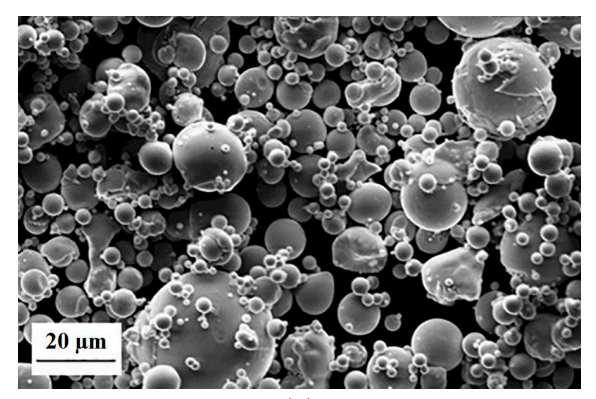

(a)

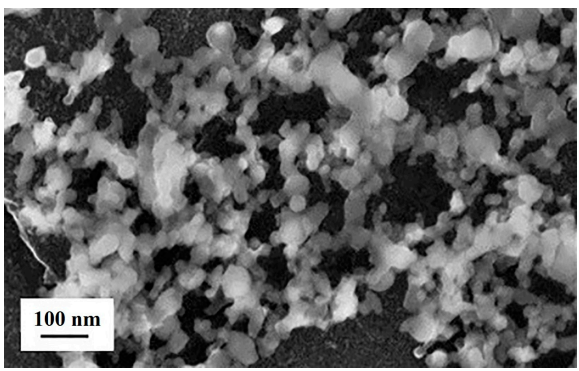

(b)

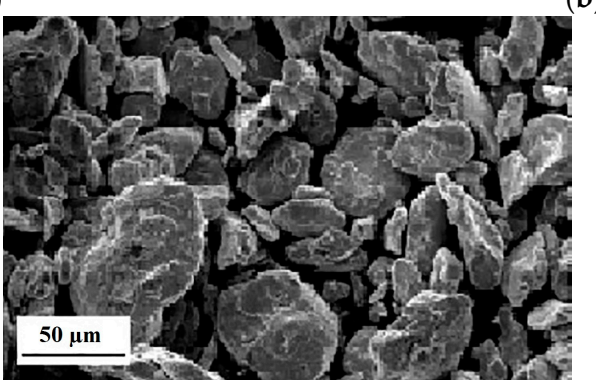

(c)

Figure 1. Powder of Fe-14Cr-1W-0.4Ti ferritic steel (a), $\mathrm{Y}_{2} \mathrm{O}_{3}(\mathbf{b})$ and of the mixture after mechanical alloying (MA) (c).

The hardness of the steel powder with $\mathrm{Y}_{2} \mathrm{O}_{3}$ is $476 \mathrm{HV}$, much higher than that of the steel powder without reinforcement $(363 \mathrm{HV})$ subjected to MA in the same conditions. The extra hardening is the effect of mechanically activated diffusion phenomena leading to in-situ nano-precipitation of reinforcing oxides. More importantly, heat treatments of $2 \mathrm{~h}$ up to $800^{\circ} \mathrm{C}$ do not affect hardness.

\subsection{Hot Extruded Material}

XRD spectra recorded on the powder before and after HE show that densification at $1100{ }^{\circ} \mathrm{C}$ leads to narrowing of peak profiles (see for example Figure 2). The analysis of peak profiles permitted to determine a dislocation density of $4 \times 10^{12} \mathrm{~m}^{-2}$ for ODS and $7.4 \times 10^{12} \mathrm{~m}^{-2}$ for the MA powder before HE while the average size of diffracting domains, namely the grains, is $\sim 400 \mathrm{~nm}$ in both the cases. In fact, peak narrowing after $\mathrm{HE}$ is only due to a decrease of dislocation density consequent to the heating during consolidation that does not affect the grain size.

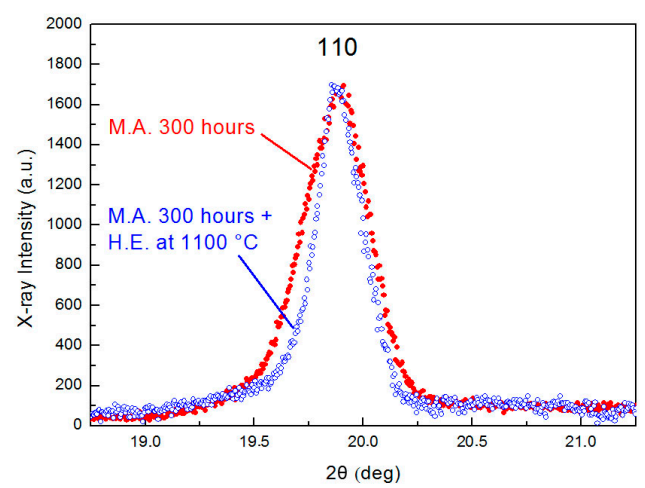

Figure 2. The $\{110\}$ XRD peak profiles of the powder before and after hot extrusion. 
Figure 3 shows the microstructure of the ODS steel after HE. The average grain size of cross sectioned grains, viewed along the extrusion axis was approximately $400 \mathrm{~nm}$; the maximum grain size observed in this orientation was $800 \mathrm{~nm}$ and there is no evidence of bimodal grain size distribution. In most regions of the matrix, a low dislocation density is observed (Figure 3a), while some areas are characterized by the presence of dislocation grooves (Figure $3 \mathrm{~b}$ ) suggesting that micro-deformations introduced by MA and subsequent $\mathrm{HE}$ are not fully homogeneous in the structure.

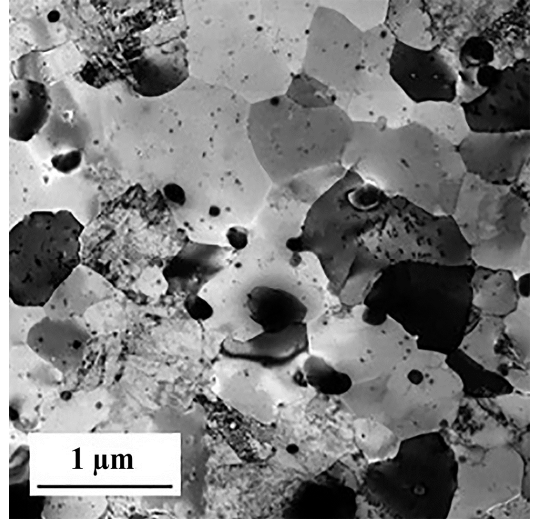

(a)

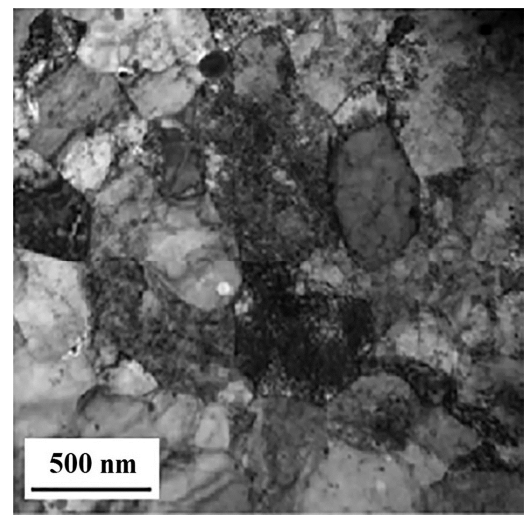

(b)

Figure 3. Transmission electron microscopy (TEM) micrographs showing microstructure of oxide dispersion strengthened (ODS) steel after hot extrusion (HE): (a) regions of low density and (b) high density of dislocations within ferrite grains.

As shown in Figure 4a,b, two types of particles have been observed in TEM.

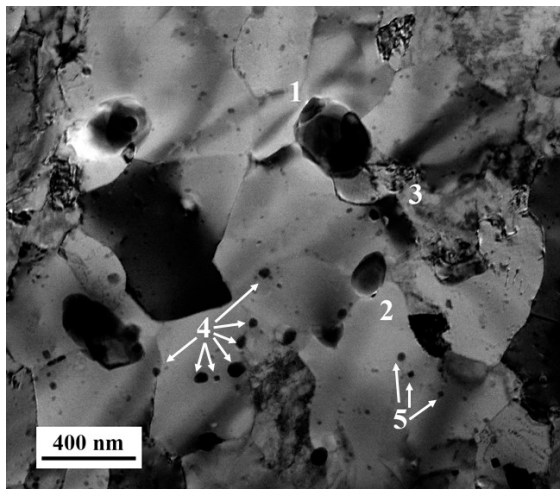

(a)

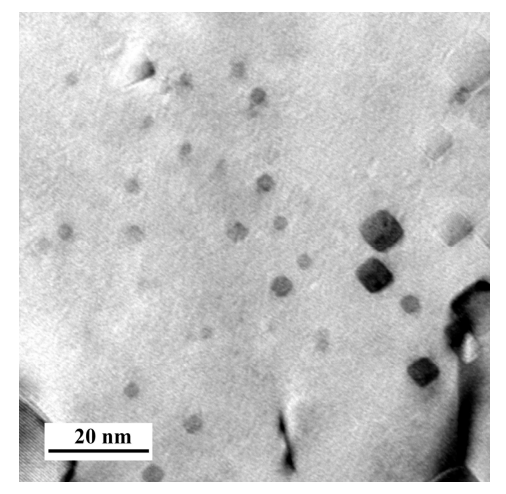

(b)

Figure 4. TEM micrographs showing precipitates observed from ODS steel after HE: (a) Type 1 precipitates (points 1-5) and (b) nanometric squared Type 2 precipitates.

Type 1: Round or irregular-shaped particle not homogeneously distributed within the matrix. Their dimensions typically range from 30 to $100 \mathrm{~nm}$ with some of them reaching $300 \mathrm{~nm}$ and the chemical composition of the particles observed in hot extruded material suggests the formation of Y-Ti-oxides with different contents of titanium (Figure 4a).

Type 2: Massive precipitation of extremely fine precipitates along grain boundaries and within ferritic grains was also observed, with dimensions ranging up to $30 \mathrm{~nm}$ in diameter. In most cases, these particles display a cubic or rectangular morphology. A zone rich of type 2 particles is displayed in Figure $4 b$.

The presence of Type 2 precipitates confirms a phenomenon reported in literature (e.g., see $[1,24])$, i.e., the addition of a small amount of Ti in steel composition strongly favours the precipitation of 
oxide particles to nanometric size. In literature, particles with the same cubic shape and size have been identified as $\mathrm{Y}_{2} \mathrm{Ti}_{2} \mathrm{O}_{7}[25,26]$.

Tensile tests show that ODS exhibits higher mechanical performances than the unreinforced steel (Figure 5a-c). In tests carried out from room temperature up to $400{ }^{\circ} \mathrm{C}$ yield stress (YS) and ultimate tensile strength (UTS) of the unreinforced steel (steel matrix) are much smaller (about $40 \%$ ) than those of ODS; at higher temperatures the difference tends progressively to decrease and at $700{ }^{\circ} \mathrm{C}$ the values are similar. To understand such behaviour observed above $400{ }^{\circ} \mathrm{C}$ the ends (not deformed) of probes broken at high temperature have been subjected to micro-hardness tests and metallographic examination but no remarkable structural and mechanical differences were observed before and after the tensile tests at different temperatures. On the other hand, as reported in the previous section, ODS steel is so stable that a heat treatment of $2 \mathrm{~h}$ at $800^{\circ} \mathrm{C}$ does not modify its hardness. Therefore, the progressive decrease of mechanical performances above $400{ }^{\circ} \mathrm{C}$ can be ascribed to the ease of dislocation depinning from nano-particles and nano-precipitates as temperature increases instead permanent structure changes.

It is noticeable that a "ductility valley" is observed in the area reduction (AR\%) plot (Figure $5 \mathrm{c}$ ) of ODS steel at about $400{ }^{\circ} \mathrm{C}$; a similar behaviour for the MA957 alloy (Fe-14Cr-1Ti-0.3Mo-0.25 $\mathrm{Y}_{2} \mathrm{O}_{3}$ ) has been already reported in literature [27].

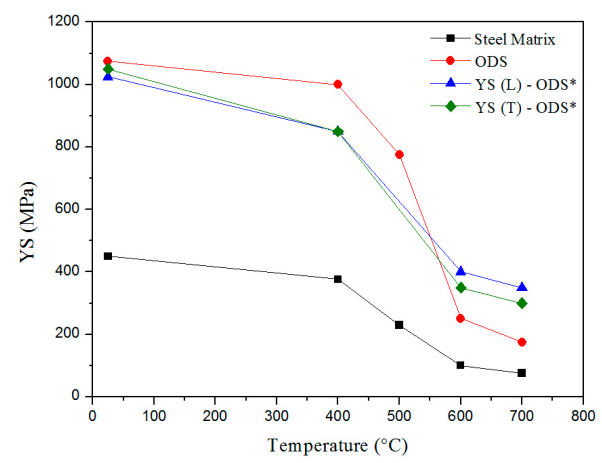

(a)

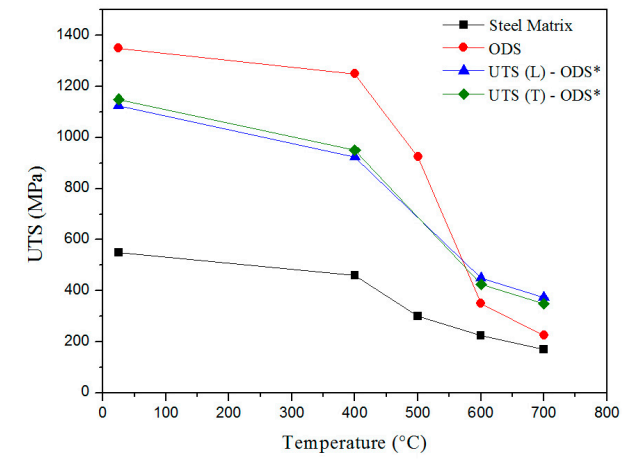

(b)

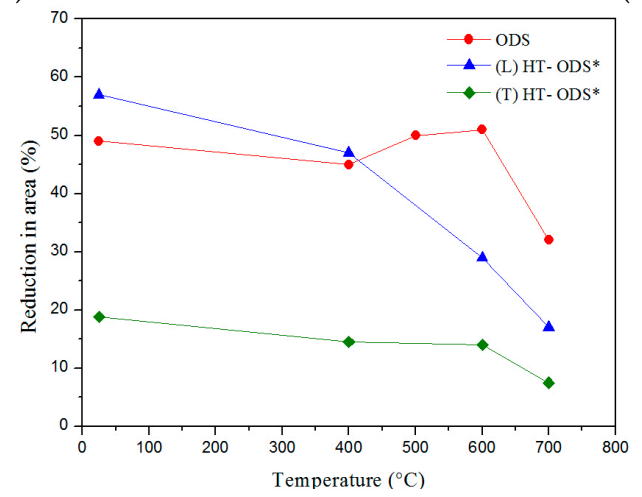

(c)

Figure 5. The tensile behavior at increasing test temperature of the examined ODS steel is compared with that of unreinforced steel (steel matrix) and of ODS*, a material prepared through the conventional route (high-energy $\mathrm{MA} / \mathrm{HE}$ at $1100{ }^{\circ} \mathrm{C} /$ heat treatment of $1.5 \mathrm{~h}$ at $1050{ }^{\circ} \mathrm{C}$ ) [28]: (a) Ultimate Tensile Stress (UTS); (b) Yield Stress (YS); and (c) Area reduction. Data adapted from [28] refer to samples taken along longitudinal $(\mathrm{L})$ and transverse $(\mathrm{T})$ directions.

\subsection{Heat Treated ODS Steel}

The ODS steel has been submitted to heat treatments at different temperatures $(1050,1100$, and $1150{ }^{\circ} \mathrm{C}$ ) for $30 \mathrm{~min}$ of soaking time to evaluate the microstructural and mechanical stability after exposure at high temperature. As shown in Table 1, hardness after heat treatments decreases to about 
$70 \%$ of the original value of ODS steel and small variations, comparable with experimental data scattering, are observed between the samples treated at the three temperatures.

Table 1. The ODS material has been examined in as-prepared condition (samples HE) and after heat treatments at three different temperatures $\left(1050,1100\right.$, and $\left.1150{ }^{\circ} \mathrm{C}\right)$ for $30 \mathrm{~min}$. The corresponding final hardness is reported.

\begin{tabular}{cccc}
\hline Sample & Temperature $\left({ }^{\circ} \mathbf{C}\right)$ & Time $(\mathbf{m i n})$ & Hardness HV \\
\hline $\mathrm{HE}$ & No & No & $447 \pm 5$ \\
$\mathrm{HE}+1050^{\circ} \mathrm{C} / 30 \mathrm{~min}$ & 1050 & 30 & $315 \pm 6$ \\
$\mathrm{HE}+1100^{\circ} \mathrm{C} / 30 \mathrm{~min}$ & 1100 & 30 & $327 \pm 10$ \\
$\mathrm{HE}+1150^{\circ} \mathrm{C} / 30 \mathrm{~min}$ & 1150 & 30 & $305 \pm 4$ \\
\hline
\end{tabular}

XRD spectra of the HE material before and after the examined heat treatments display a change of the relative intensities of the strongest Fe reflections, i.e., $\{110\},\{200\}$, and $\{211\}$, testifying a partial re-orientation of crystalline grains. The intensities (normalized to 100) are reported in Table 2.

Table 2. Intensities (normalized to 100) of the most strong reflections in the XRD spectra of hot extruded material (HE), and hot extruded plus heat treated at $1050{ }^{\circ} \mathrm{C}(\mathrm{A}), 1100{ }^{\circ} \mathrm{C}(\mathrm{B})$, and $1150{ }^{\circ} \mathrm{C}(\mathrm{C})$ for $30 \mathrm{~min}$.

\begin{tabular}{ccccc}
\hline $\begin{array}{c}\text { Intensities of the Most } \\
\text { Strong Reflections }\end{array}$ & $\mathbf{H E}$ & $\begin{array}{c}\mathbf{A} \\
\left.\mathbf{( H E}+\mathbf{1 0 5 0}{ }^{\circ} \mathbf{C} / \mathbf{3 0} \mathbf{~ m i n}\right)\end{array}$ & $\begin{array}{c}\mathbf{B} \\
\left.\mathbf{( H E}+\mathbf{1 1 0 0}{ }^{\circ} \mathbf{C} / \mathbf{3 0} \mathbf{~ m i n}\right)\end{array}$ & $\begin{array}{c}\mathbf{C} \\
\left.\mathbf{( H E}+\mathbf{1 1 5 0}{ }^{\circ} \mathbf{C} / \mathbf{3 0} \mathbf{~ m i n}\right)\end{array}$ \\
\hline$I_{110}$ & 100 & 100 & 100 & 100 \\
$I_{200}$ & 37 & 41 & 36 & 49 \\
$I_{211}$ & 43 & 61 & 50 & 59 \\
\hline
\end{tabular}

TEM examinations of heat treated samples confirm XRD results; an example is displayed in Figure 6 (sample heat treated at $1150{ }^{\circ} \mathrm{C}$ for $30 \mathrm{~min}$ ). Figure 6 evidences an inhomogeneous ferritic structure: part of the grains exhibits a size of $\sim 500 \mathrm{~nm}$ comparable to the original size after HE while another part has a larger size of about $4 \mu \mathrm{m}$.

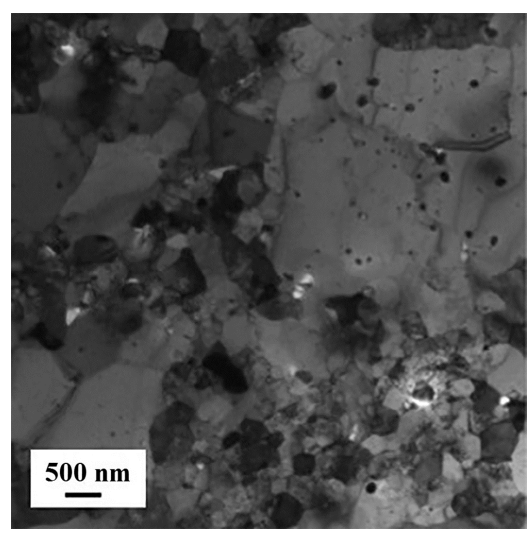

(a)

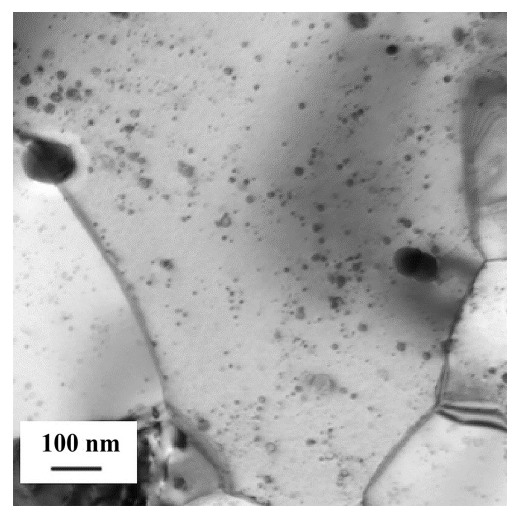

(b)

Figure 6. TEM micrograph of ODS sample after heat treatment at $1150{ }^{\circ} \mathrm{C}$ for $30 \mathrm{~min}$. (a) Bimodal grain size distribution. (b) Nanosized precipitates inside a ferritic grain of small size.

As shown in Figure $6 \mathrm{~b}$, the volume fraction of nanosized precipitates is significantly higher in the regions of small ferrite grains, suggesting that grain coarsening in some regions is favoured by an uneven distribution of small sized Y-Ti-oxides. Therefore, hardness decrease in heat treated samples depends on both grain coarsening in part of the material and defect recovery, with lower dislocation density. 


\section{Discussion}

An important issue was to verify how the ODS steel behaves with respect to similar materials prepared through the conventional process. Serrano et al. [28] produced and tested an ODS steel with powders of the same nominal composition (Fe-14Cr-1W-0.4Ti) and the same proportion of $\mathrm{Y}_{2} \mathrm{O}_{3}$ $(0.3 \mathrm{wt} \%)$ using high-energy MA, HE at $1100{ }^{\circ} \mathrm{C}$, and final annealing of $1.5 \mathrm{~h}$ at $1050{ }^{\circ} \mathrm{C}$. Therefore, this material, hereinafter indicated as ODS*, has been considered for comparison and related data have been reported in Figure 5a-c. ODS* exhibits grains elongated along the extrusion direction with bimodal size distribution and consequently the mechanical properties are anisotropic, thus the values measured along both the directions, parallel $(\mathrm{L})$ and perpendicular $(\mathrm{T})$ to extrusion, are shown. For temperatures up to $500{ }^{\circ} \mathrm{C}$ YS and UTS values of ODS* are lower than those of the material prepared by low-energy MA, whereas they become a little higher from $600{ }^{\circ} \mathrm{C}$ upwards.

The area reduction values of ODS* are quite different in $\mathrm{L}$ and $\mathrm{T}$ directions, in particular the material exhibits low ductility along T. The A (\%) value of the ODS prepared by us is a little lower than that measured in ODS* along L direction up to $400{ }^{\circ} \mathrm{C}$ and always better along the Tdirection.

To understand the temperature-dependent mechanical properties of the ODS steel the contributions of different strengthening mechanisms have been considered: (i) solid solution $\left(\sigma_{\mathrm{SS}}\right)$; (ii) Bailey-Hirsch $\left(\sigma_{\mathrm{BH}}\right)$ due to dislocations; (iii) Hall-Petch $\left(\sigma_{\mathrm{HP}}\right)$; (iv) Orowan $\left(\sigma_{K}\right)$ [29]; and (v) Arzt-Rősler-Wilkinson $\left(\sigma_{\mathrm{ARW}}\right)$ for interfacial pinning [30,31].

(i) In the case of examined ODS steel the solid solution strengthening mainly depends on the amounts of $\mathrm{Cr}$ and $\mathrm{W}$ and may be evaluated as [32]:

$$
\sigma_{\mathrm{SS}}=0.00689 k C^{n}
$$

In Equation (3) $C$ is the concentration (at \%) of the elements, $n=0.75$ and the coefficient $k$ is 1400 for $\mathrm{Cr}$ and 11,000 for $\mathrm{W}$ [33]. The specific contributions result to be $70 \mathrm{MPa}$ for $\mathrm{Cr}$ and $30 \mathrm{MPa}$ for $\mathrm{W}$, thus the total $\sigma_{\mathrm{SS}}=100 \mathrm{MPa}$.

(ii) The Bailey-Hirsch stress is expressed by the relationship:

$$
\sigma_{\mathrm{BH}}=M \alpha G b \rho^{1 / 2}
$$

where $M=2.9$ the Taylor factor for bcc metals, the parameter $\alpha=0.24$ [34], $G$ the shear modulus, $b=0.25 \mathrm{~nm}$ the modulus of Burgers vector and $\rho=4 \times 10^{12} \mathrm{~m}^{-2}$ the dislocation density determined by XRD. The shear modulus vs. temperature (G-T) curve, measured by MS, is shown in Figure 7.

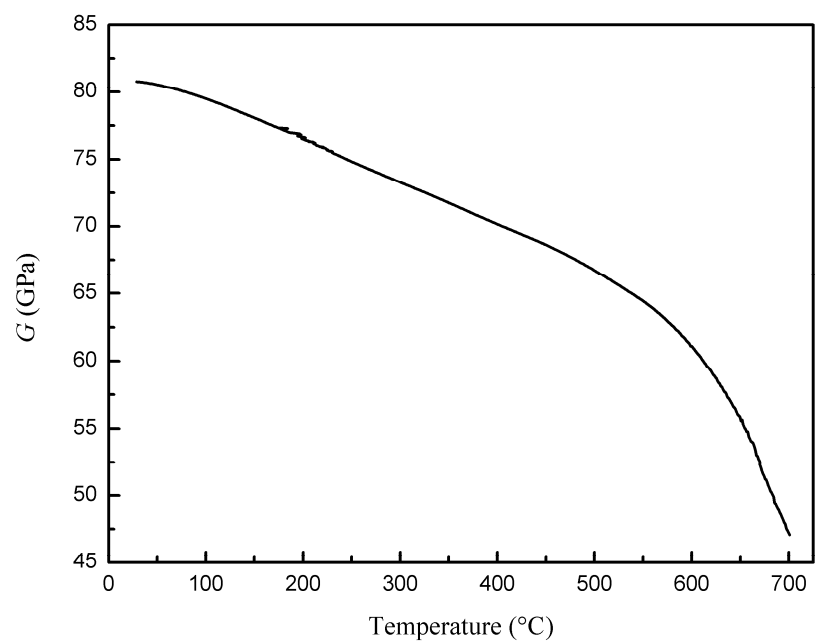

Figure 7. Shear modulus G vs. temperature determined from Mechanical Spectroscopy (MS) tests. 
(iii) The Hall-Petch stress $\left(\sigma_{\mathrm{HP}}\right)$ vs. temperature $T$ is given by:

$$
\sigma_{\mathrm{HP}}(T)=\sigma_{0}+\sigma_{\mathrm{D}}=\sigma_{0}+[G(T) / G(300 K)]^{1 / 2} K D^{-1 / 2},
$$

where $\sigma_{0}$ is the friction stress, i.e., the matrix yield stress for a grain of theoretically infinite size, which was evaluated to be $\sim 13 \mathrm{MPa}$ [35], $K=0.18 \mathrm{MPa} \mathrm{m}^{1 / 2}$ and the average grain size $D=400 \mathrm{~nm}$. In fact, as discussed by Schneibel et al. [36], such mechanism losses his efficiency as the effect of Coble creep becomes predominant (Hall-Petch breakdown), namely when $\sigma_{\mathrm{CC}}<\sigma_{\mathrm{HP}}$. The stress $\sigma_{\mathrm{CC}}$ due to Coble creep is calculated as:

$$
\sigma_{\mathrm{CC}}=\frac{k_{b} T D^{3} \dot{\varepsilon}}{47 \Omega \delta_{\mathrm{B}} D_{\mathrm{B}}} \exp \left(Q_{\mathrm{B}} / R T\right)
$$

where Boltzmann constant $k_{b}=1.38 \times 10^{-23} \mathrm{~J} / \mathrm{K}, \dot{\varepsilon}=10^{-3} \mathrm{~s}^{-1}$, the atomic volume $\Omega=1.18 \times 10^{-29} \mathrm{~m}^{3}$, the product of grain boundary width and pre-exponential factor of grain boundary diffusion $\delta_{\mathrm{B}} D_{\mathrm{B}}=1.1 \times 10^{-12} \mathrm{~m}^{3} / \mathrm{s}$, the activation energy for grain boundary diffusion $Q_{\mathrm{B}}=174 \mathrm{~kJ} / \mathrm{mol}$, the gas constant $R=8.31 \mathrm{~J} / \mathrm{mol} \mathrm{K}$.

(iv) The Orowan critical stress $\left(\sigma_{\mathrm{K}}\right)$ is determined through the relationship of Kocks [29]:

$$
\sigma_{\mathrm{K}}=0.9 M \frac{[\ln (\pi d / b)]^{3 / 2}}{[\ln (L / b)]^{1 / 2}} \frac{[G b / 4 \pi(1-v)]}{[L-(\pi d / 4)]}
$$

$v=0.3$ is the Poisson's ratio, $L=63 \mathrm{~nm}$ and $d=18 \mathrm{~nm}$ are the mean spacing between particles and particle size, respectively, determined from TEM observations (average values of 20 micrographs).

(v) The Arzt-Rősler-Wilkinson stress $\left(\sigma_{\mathrm{ARW}}\right)$, connected to the process of dislocation climb over hard particles, can be written according to the equation proposed by Reppich [37] as:

$$
\sigma_{\mathrm{ARW}}=0.9 M \frac{R^{3 / 2}}{2 \sqrt{2}+R^{3 / 2}} \frac{G b}{L}
$$

where $R=0.77$ represents the decrease of line tension of a pinned dislocation segment.

On these grounds, the yield stress of ODS steel measured by tensile tests carried out at increasing temperatures (Figure $5 \mathrm{~b}$ ) can be compared with the overall stress $\sigma_{Y}$ calculated taking into account the aforesaid mechanisms:

$$
\sigma_{\mathrm{Y}}=\sigma_{\mathrm{SS}}+\sigma_{\mathrm{BH}}+\sigma_{0}+\sigma_{\mathrm{D}}+\sigma_{\mathrm{K}}+\sigma_{\mathrm{ARW}}+\sigma_{\mathrm{CC}}
$$

The relative amount of each strengthening contribution plays a different role depending on the temperature range. The strengthening contributions to yield stress at increasing temperature are reported in Table 3.

Table 3. Strengthening contributions to yield stress at $25,400,500,600$, and $700{ }^{\circ} \mathrm{C}$ for ODS steel.

\begin{tabular}{cccccc}
\hline \multirow{2}{*}{ Strengthening Contributions to Yield Stress (MPa) } & \multicolumn{5}{c}{ Temperature $\left({ }^{\circ} \mathbf{C}\right)$} \\
\cline { 2 - 6 } & $\mathbf{2 5}$ & $\mathbf{4 0 0}$ & $\mathbf{5 0 0}$ & $\mathbf{6 0 0}$ & $\mathbf{7 0 0}$ \\
\hline$\sigma_{\mathrm{SS}}$ & 100 & 100 & 100 & 100 & 100 \\
$\sigma_{\mathrm{BH}}$ & 28 & 24 & 23 & 21 & 16 \\
$\sigma_{0}$ & 13 & 13 & 13 & 13 & 13 \\
$\sigma_{\mathrm{D}}$ & 285 & 265 & 259 & - & - \\
$\sigma_{\mathrm{K}}$ & 657 & 571 & 543 & - & - \\
$\sigma_{\mathrm{ARW}}$ & - & - & 133 & 122 & 94 \\
$\sigma_{\mathrm{CC}}$ & - & - & 285 & 16 & 2 \\
$\sigma_{\mathrm{SS}}+\sigma_{\mathrm{BH}}+\sigma_{0}+\sigma_{\mathrm{D}}+\sigma_{\mathrm{K}}(\mathrm{ODS}$ steel) & 1083 & 973 & 938 & - & - \\
$\sigma_{\mathrm{SS}}+\sigma_{\mathrm{BH}}+\sigma_{0}+\sigma_{\mathrm{CC}}+\sigma_{\mathrm{ARW}}(\mathrm{ODS}$ steel) & - & - & 554 & 272 & 225 \\
\hline
\end{tabular}


Figure 8 compares the sum of all the strengthening contributions and the experimental yield stress of ODS. In fact, from room temperature up to $\sim 500{ }^{\circ} \mathrm{C}$ the yield stress is due to the solid solution $\left(\sigma_{\mathrm{SS}}\right)$, dislocations $\left(\sigma_{\mathrm{BH}}\right)$, Hall-Petch $\left(\sigma_{0}+\sigma_{\mathrm{D}}\right)$, and Orowan $\left(\sigma_{\mathrm{K}}\right)$ contributions. In the temperature range 500-600 ${ }^{\circ} \mathrm{C}$, the component $\sigma_{\mathrm{D}}$ undergoes a progressive breakdown confirming the trend reported previously in literature [36]. In addition, the Orowan stress $\left(\sigma_{\mathrm{K}}\right)$ losses its efficiency above $500{ }^{\circ} \mathrm{C}$ [38], so from this temperature the term $\sigma_{\mathrm{K}}$ is substituted by $\sigma_{\mathrm{ARW}}$.

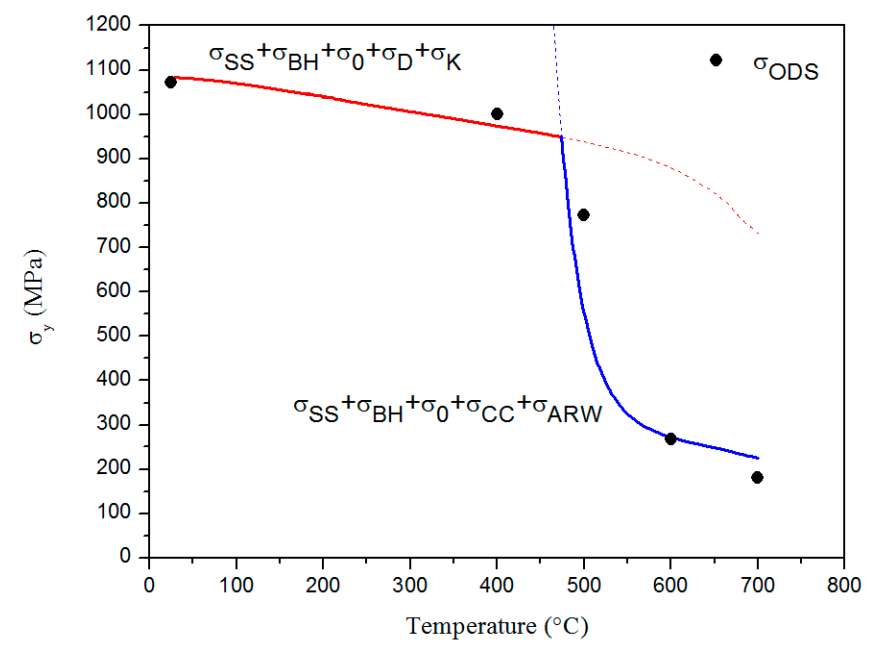

Figure 8. Yield stress values of ODS are compared with different strengthening contributions, namely solid solution $\left(\sigma_{S S}\right)$, dislocations $\left(\sigma_{\mathrm{BH}}\right)$, friction stress $\left(\sigma_{0}\right)$, grain size $\left(\sigma_{\mathrm{D}}\right)$, Orowan $\left(\sigma_{\mathrm{K}}\right)$, Arzt-Rősler-Wilkinson $\left(\sigma_{\mathrm{ARW}}\right)$, and Coble creep $\left(\sigma_{\mathrm{CC}}\right)$.

With respect to the conventional preparation route that examined here leads to very fine equiaxed grains instead of a bimodal grain size distribution with grains of several tenths of microns. Such a feature is fundamental in determining its better mechanical properties in the temperature range up to $500{ }^{\circ} \mathrm{C}$. At higher temperatures, the component $\sigma_{\mathrm{D}}$ breakdowns the material obtained through the conventional route with finer distribution of oxide particles exhibits a little higher values of yield stress.

\section{Conclusions}

Nano-ODS Fe-14Cr-1W-0.4Ti steel with $\mathrm{Y}_{2} \mathrm{O}_{3}$ particles (0.3 wt. \%) has been produced by low-energy MA and successive HE. The main conclusions of this study are:

(i) The method permits treatment of large amounts of powder in the order of kilograms.

(ii) The material has equiaxed grains (mean size of $400 \mathrm{~nm}$ ) and a dislocation density of $4 \times 10^{12} \mathrm{~m}^{-2}$. Two types of second phase particles were observed: (i) round or irregular-shaped Y-Ti-oxides with different contents of titanium; (ii) cubic or rectangular fine precipitates of few nanometers. Therefore, low-energy MA decomposes $\mathrm{Y}_{2} \mathrm{O}_{3}$ into $\mathrm{Y}$ and $\mathrm{O}$ atoms, which are then bonded with Ti and precipitate to form extremely fine Y-Ti-O complex oxides during HE. Nano-oxides are stable up to $800{ }^{\circ} \mathrm{C}$ and guarantee the stability of microstructure and mechanical properties.

(iii) With respect to the conventional preparation route fine equiaxed grains are observed instead of a bimodal grain size distribution. This microstructure involves better mechanical properties up to $500{ }^{\circ} \mathrm{C}$, however, the precipitate distribution in the matrix is not so homogeneous as that obtained from high-energy MA, thus at higher temperature, where the Petch-Hall contribution breakdowns and the role played by precipitate in strengthening is dominant, YS and UTS remarkably decrease and are a little lower than those of conventional ODS steels.

(iv) ODS steel heat treated above $1000{ }^{\circ} \mathrm{C}$ exhibits defect recovery and partial grain growth that can be also ascribed to the not homogeneous original distribution of $\mathrm{Y}_{2} \mathrm{O}_{3}$ particles. 
(v) In conclusion the examined method seems promising but a longer time of MA seems necessary for achieving a more homogeneous distribution of nano-oxides and consequently further enhancing mechanical properties at high temperature.

Author Contributions: Claudio Testani made MA and heat treatments, Alessandra Fava, Gianfranco Lovicu, and Massimo De Sanctis performed TEM observations; Alessandra Fava and Gianfranco Lovicu performed tensile tests, Alessandra Varone, Maria Richetta, and Roberto Montanari performed microhardness tests, XRD experiments and mechanical spectroscopy to determine the E vs. T curve. All the authors contributed to analyze the results and write the manuscript.

Conflicts of Interest: The authors declare no conflict of interest.

\section{References}

1. Ukai, S.; Harada, M.; Okada, H.; Inoue, M.; Nomura, S.; Shikakura, S.; Asabe, K.; Nishida, T.; Fujiwara, M. Alloying design of oxide dispersion strengthened ferritic steel for long life FBRs core materials. J. Nucl. Mater. 1993, 204, 65-73. [CrossRef]

2. Ukai, S.; Fujiwara, M. Perspective of ODS alloys application in nuclear environments. J. Nucl. Mater. 2002, 307-311, 749-757. [CrossRef]

3. Klueh, R.L.; Gelles, D.S.; Jitsukawa, S.; Kimura, A.; Odette, G.R.; Van der Schaaf, B.; Victoria, M. Ferritic/martensitic steels-Overview of recent results. J. Nucl. Mater. 2002, 307-311, 455-465. [CrossRef]

4. Unifantowicz, P.; Fikar, J.; Spätig, P.; Testani, C.; Maday, F.; Baluc, N.; Tran, M.Q. Optimisation of Production Method of a Nanostructured ODS Ferritic Steels. In Proceedings of the 24th IAEA Fusion Energy Conference, San Diego, CA, USA, 8-13 October 2012; p. 421.

5. Zinkle, S.J.; Busby, J.T. Structural materials for fission \& fusion energy. Mater. Today 2009, 12, 12-19.

6. De Castro, V.; Leguey, T.; Auger, M.A.; Lozano-Perez, S.; Jenkins, M.L. Analytical characterization of secondary phases and void distributions in an ultrafine-grained ODS Fe-14Cr model alloy. J. Nucl. Mater. 2011, 417, 217-220. [CrossRef]

7. De Castro, V.; Leguey, T.; Muñoz, A.; Monge, M.A.; Fernández, P.; Lancha, A.M.; Pareja, R. Mechanical and microstructural behavior of $\mathrm{Y}_{2} \mathrm{O}_{3}$ ODS EUROFER 97. J. Nucl. Mater. 2007, 367-370, 196-201. [CrossRef]

8. Brodrick, J.; Hepburn, D.J.; Ackland, G.J. Mechanism for radiation damage resistance in yttrium oxide dispersion strengthened steels. J. Nucl. Mater. 2014, 445, 291-297. [CrossRef]

9. Kimura, A. Current Status of Reduced-Activation Ferritic/Martensitic Steels R\&D for Fusion Energy. Mater. Trans. 2005, 46, 394-404.

10. Klueh, R.L.; Ehrlich, K.; Abe, F. Ferritic/martensitic steels: Promises and problems. J. Nucl. Mater. 1992, 191-194, 116-124.

11. De Carlan, Y.; Bechade, J.-L.; Dubuisson, P.; Seran, J.-L.; Billot, P.; Bougault, A.; Cozzika, T.; Doriot, S.; Hamon, D.; Henry, J.; et al. CEA developments of new ferritic ODS alloys for nuclear applications. J. Nucl. Mater. 2009, 386-388, 430-432. [CrossRef]

12. Wang, M.; Zhou, Z.; Sun, H.; Hu, H.; Li, S. Microstructural observation and tensile properties of ODS-304 austenitic steel. Mater. Sci. Eng. A 2013, 559, 287-292. [CrossRef]

13. Kawahara, M.; Kim, H.; Tokita, M. Fabrication of Nano-Materials by the Spark Plasma Sintering (SPS) Method. In Proceedings of the Powder Metallurgy World Congress, Kyoto, Japan, 12-16 November 2000; pp. 741-744.

14. Zhang, H.W.; Gopalan, R.; Mukai, T.; Hono, K. Fabrication of bulk nanocrystalline Fe-C alloy by spark plasma sintering of mechanically milled powder. Scr. Mater. 2005, 53, 863-868. [CrossRef]

15. Cabibbo, M.; Deodati, P.; Libardi, S.; Molinari, A.; Montanari, R.; Ucciardello, N. Damping of FeMo alloys obtained from SPS sintering of nanostructured powders. Mater. Sci. Forum 2009, 604-605, 203-211. [CrossRef]

16. Ji, G.; Grosdidier, T.; Bozzolo, N.; Launois, S. The mechanisms of microstructure formation in a nanostructured oxide dispersion strengthened $\mathrm{FeAl}$ alloy obtained by spark plasma sintering. Intermetallics 2007, 15, 108-118. [CrossRef]

17. Boulnat, X.; Fabregue, D.; Perez, M.; Mathon, M.-H.; De Carlan, Y. High-temperature tensile properties of nano-oxide dispersion strengthened ferritic steels produced by mechanical alloying and spark plasma sintering. Metall. Mater. Trans. A 2013, 44, 2461-2465. [CrossRef] 
18. Kasada, R.; Lee, S.G.; Isselin, J.; Lee, J.H.; Omura, T.; Kimura, A.; Okuda, T.; Inoue, M.; Ukai, S.; Ohnuki, S.; et al. Anisotropy in tensile and ductile-brittle transition behavior of ODS ferritic steels. J. Nucl. Mater. 2011, 417, 180-184. [CrossRef]

19. Hilger, I.; Boulnat, X.; Hoffmann, J.; Testani, C.; Bergner, F.; De Carlan, Y.; Ferraro, F.; Ulbricht, A. Fabrication and characterization of oxide dispersion strengthened (ODS) $14 \mathrm{Cr}$ steels consolidated by means of hot isostatic pressing, hot extrusion and spark plasma sintering. J. Nucl. Mater. 2016, 472, 206-214. [CrossRef]

20. Magini, M.; Iasonna, A. Energy Transfer in Mechanical Alloying (Overview). Mater. Trans. JIM 1995, 36, 123-133. [CrossRef]

21. Klug, H.P.; Alexander, L.E. X-ray Diffraction Procedures for Polycrystalline and Amorphous Materials, 2nd ed.; John Wiley \& Sons: New York, NY, USA, 1974.

22. Williamson, G.K.; Smallman, R.E. III. Dislocation densities in some annealed and cold-worked metals from measurements on the X-ray Debye-Scherrer spectrum. Philos. Mag. 1956, 1, 34-46. [CrossRef]

23. Amadori, S.; Campari, E.G.; Fiorini, A.L.; Montanari, R.; Pasquini, L.; Savini, L.; Bonetti, E. Automated resonant vibrating-reed analyzer apparatus for a non-destructive characterization of materials for industrial applications. Mater. Sci. Eng. A 2006, 442, 543-546. [CrossRef]

24. Okuda, T.; Fujiwara, M. Dispersion behavior of oxide particles in mechanically alloyed ODS steel. J. Mater. Sci. Lett. 1995, 14, 1600-1603. [CrossRef]

25. Dawson, K.; Tatlock, G.J. Characterisation of nanosized oxides in ODM401 oxide dispersion strengthened steel. J. Nucl. Mater. 2014, 444, 252-260. [CrossRef]

26. Oka, K.; Ohnuki, S.; Yamashita, S.; Akasaka, N.; Ohtsuka, S.; Tanigawa, H. Structure of Nano-Size oxides in ODS Steels and Its Stability under Electron Irradiation. Mater. Trans. 2007, 48, 2563-2566. [CrossRef]

27. Alamo, A.; Lambard, V.; Averty, X.; Mathon, M.H. Assessment of ODS- $14 \%$ Cr ferritic alloy for high temperature applications. J. Nucl. Mater. 2004, 329-333, 333-337. [CrossRef]

28. Serrano, M.; Hernández-Mayoral, M.; García-Junceda, A. Microstructural anisotropy effect on the mechanical properties of a 14Cr ODS steel. J. Nucl. Mater. 2012, 428, 103-109. [CrossRef]

29. Kocks, U.F. The theory of an obstacle-controlled yield strength-Report after an international workshop. Mater. Sci. Eng. A 1977, 27, 291-298. [CrossRef]

30. Arzt, E.; Wilkinson, D.S. Threshold stresses for dislocation climb on hard particles: The effect of an attractive interaction. Acta Metall. 1986, 34, 1893-1898. [CrossRef]

31. Arzt, E.; Rösler, J. The kinetics of dislocation climb over hard particles-II. Effects of an attractive particle-dislocation interaction. Acta Metall. 1988, 36, 1053-1060. [CrossRef]

32. Li, Q. Modeling the microstructure-mechanical property relationship for a $12 \mathrm{Cr}-2 \mathrm{~W}-\mathrm{V}-\mathrm{Mo}-\mathrm{Ni}$ power plant steel. Mater. Sci. Eng. A 2003, 361, 385-391. [CrossRef]

33. Shen, J.; Li, Y.; Li, F.; Yang, H.; Zhao, Z.; Kano, S.; Matsukawa, Y.; Satoh, Y.; Abe, H. Microstructural characterization and strengthening mechanisms of a 12Cr-ODS steel. Mater. Sci. Eng. A 2016, 673, 624-632. [CrossRef]

34. Kocks, U.F.; Mecking, H. Physics and phenomenology of strain hardening: The FCC case. Prog. Mater. Sci. 2003, 48, 171-273. [CrossRef]

35. Takaki, S.; Akama, D.; Nakada, N.; Tsuchiyama, T. Effect of grain boundary segregation of interstitial elements on Hall-Petch coefficient in steels. Mater. Trans. 2014, 55, 28-34. [CrossRef]

36. Schneibel, J.H.; Heilmaier, M. Hall-petch breakdown at elevated temperatures. Mater. Trans. 2015, 55, 44-51. [CrossRef]

37. Reppich, B. On the attractive particle-dislocation interaction in dispersion-strengthened material. Acta Mater. 1998, 46, 61-67. [CrossRef]

38. Steckmeyer, A.; Praud, M.; Fournier, B.; Malaplate, J.; Garnier, J.; Béchade, J.L.; Tournié, I.; Tancray, A.; Bougault, A.; Bonnaillie, P. Tensile properties and deformation mechanisms of a 14Cr ODS ferritic steel. J. Nucl. Mater. 2010, 405, 95-100. [CrossRef]

(C) 2017 by the authors. Licensee MDPI, Basel, Switzerland. This article is an open access article distributed under the terms and conditions of the Creative Commons Attribution (CC BY) license (http:// creativecommons.org/licenses/by/4.0/). 